\title{
A Novel Class F Fly Ash-Based Geopolymer and Its Application in Coal Mine Grouting
}

\author{
Luchang Xiong, Zhijun Wan $\mathbb{D}^{D}$, Shubing Qin, Peng Shi, Junhui Wang ${ }^{(D)}$, and \\ Zhaopeng Wu
}

Key Laboratory of Deep Coal Resource Mining (CUMT), Ministry of Education of China, School of Mines, China University of Mining and Technology, Xuzhou, Jiangsu 221116, China

Correspondence should be addressed to Zhijun Wan; zhjwan@cumt.edu.cn

Received 25 September 2020; Revised 29 October 2020; Accepted 30 October 2020; Published 17 November 2020

Academic Editor: Mehmet Serkan KIRGIZ

Copyright $(2020$ Luchang Xiong et al. This is an open access article distributed under the Creative Commons Attribution License, which permits unrestricted use, distribution, and reproduction in any medium, provided the original work is properly cited.

The novel class F fly ash-based geopolymer, largely made of fly ash from the coal solid waste, was used as a kind of grouting material in the coal and electricity-integrated mine from which the solid waste comes, for the purpose of in situ utilization of fly ash. The ratio experiment of material, designed through the orthogonal method, was used to study material properties such as fluidity and strength which are important to the application of mine grouting, and the optimal material proportioning scheme for Green Fly Ash-based grouting material is determined. It has been found out that there was serious rib spalling, roof deformation, obvious floor heave, crack development, and some water seepage in the permanent refuge chamber of the mine. Therefore, to solve these problems, a specific scheme of grouting reinforcement for the surrounding rocks of the permanent refuge chamber and roadway in this mine was designed. Through an analysis of the reinforcement effect of the cementation of surrounding rock after the grouting process, it can be concluded that the green fly ash-based polymer as grouting material can well penetrate into the cracks of the broken surrounding rock and get fully cemented with the surrounding rock and that it can reduce the deformation of the surrounding rock effectively, increase the integrity, and improve the carrying capacity of the surrounding rock. Besides, the grouting reinforcement effect of surrounding rock was verified through numerical simulation, and the grouting process design of green fly ash-based polymer mine was discussed. This study can provide a green and economical approach to the in situ utilization of fly ash which is a kind of coal solid waste.

\section{Introduction}

With the increasing depletion of coal resources in Eastern China, the hub of coal industry has been gradually transferred to Northwestern China with abundant coal resources, resulting in an urgent need for adjustment of the traditional mode of coal mining and utilizing $[1,2]$. However, Eastern China is still the main place where coal-consuming industry pervades, which requires and promotes the large-scale application of industrial mode of coal-electricity integration largely, and this mode means that the coal will be transformed into electricity in Northwestern China instead of being transferred to Eastern China, and then, the electricity will be transferred to Eastern China to provide electricity supply for the industrial purpose there $[3,4]$. Northwestern China is abundant in natural resources, yet its ecological environment is very fragile. There is a large amount of industrial waste resulting from coal mining and coal-fired power generation, which will cause irreparable damage to the ecological environment $[5,6]$. Coal-electricity integration industry will produce a large amount of solid waste such as fly ash and coal gangue. For coal gangue, it can stay inside the well in China so as not to cause harm to the environment. However, the fly ash can become a kind of solid waste pollutant which causes a great deal of harm to the ecological environment if it is not well stacked in the power plant [7]. Although the fly ash has become a common raw material for construction [8-11], most of the fly ash can only be carelessly disposed due to the remoteness of the places where the transformation of coal into electricity happens in Northwestern China and a lack of enough market for the 
consumption of the fly ash as a construction material, resulting in huge harm to the ecological environment.

The coal mines for coal-electricity integration in Northwestern China are characterized by shallow burial, soft surrounding rock in the mine chamber and roadway, and high degree of brokenness after mining disturbance, resulting in the occurrences such as difficulty in surrounding rock support. Mine grouting is a quite effective way of surrounding rock reinforcement. After the operation of grouting reinforcement, the integrity of the surrounding rock can be increased, thus improving its carrying capacity [12-14]. The usual chemical grouting materials are very expensive, and cement as a grouting material has the problems of short time for initial setting and limited grouting depth, resulting in the need for a new type of material for mine grouting which is economical with a good performance [15-18]. As a kind of silicate material with high potential activity, fly ash has good physical and chemical properties of its own, which contributes to its wide application in all kinds of construction materials. There have been a large number of studies on the application of fly ash in construction materials at home and abroad [19-23]. The fly ash-based polymer made of fly ash is a kind of cementing material with excellent performance, and the fly ash can be made into mine grouting material which can satisfy the need for fluidity and strength through a reasonable ratio experiment.

In this study, the mine grouting material was made from green fly ash-based geopolymer meeting the performance requirements for mine grouting material through ratio experiment in the laboratory. Also, the project was conducted in the Dananhu No. 1 Coal Mine. The schematic design of the grouting reinforcement, grouting process, and grouting effect testing of the application of green fly ashbased geopolymer in Dananhu No. 1 Coal Mine was analyzed and discussed through ways such as on-site investigation, theoretical analysis, and numerical simulation. This study can provide a more detailed case guidance for in situ utilization of fly ash in the mine.

\section{Material Preparation}

2.1. Raw Material Selection. Through a lot of ratio experiments in the early stage, the fly ash-based materials have been studied deeply, and the properties and functions of various raw materials have been well obtained. Based on ratio experiments, fly ash, cement, sodium silicate, silica fume, and calcium chloride were selected as the main raw materials in this study to make green fly ash-based grouting materials. The raw material samples are shown in Figure 1. The cement used in the project is OPC (ordinary Portland cement) 42.5 from Xuzhou Huaihai, and the fly ash is from Dananhu power plant in Xinjiang. As the main cementitious base for the grouting material based on green fly ash, cement is the main contributor to gelation of the raw materials in the early stage, and the high potential activity of fly ash ensures the improvement of material strength and stability in the later stage [24]. Sodium silicate is a commonly used alkali activator for fly ash, which can gradually react with fly ash to

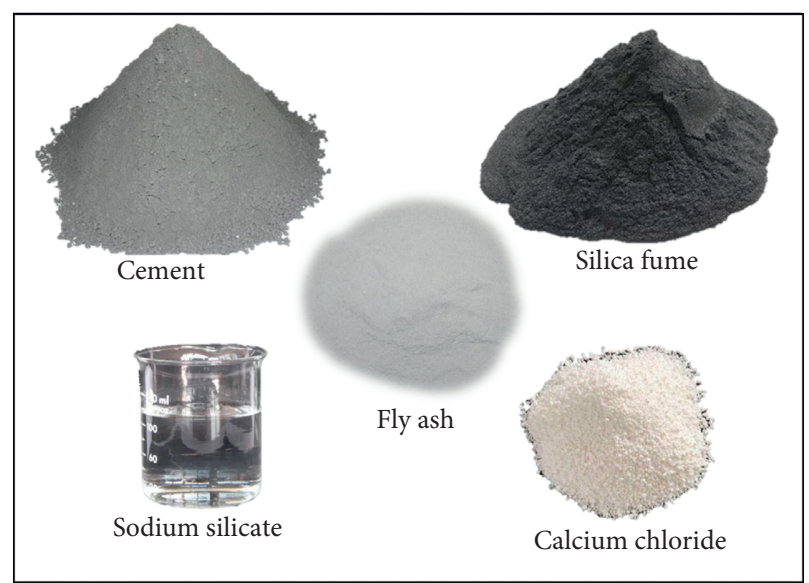

FIgURE 1: The raw material for grouting material.

stimulate the potential pozzolanic activity of fly ash under the influence of water. In this study, liquid sodium silicate, produced by Shandong Usolf, with more than 34\% of sodium silicate is selected. Silica fume and calcium chloride were purchased, respectively, from Henan Borun New Materials Co., Ltd. (purity $>95 \%$ ) and Shanghai Sinopharm Chemical Reagent Co., Ltd. (purity > 96\%). Although these two kinds of raw materials are used in small amount, they are also indispensable parts of the grouting material.

2.2. Orthogonal Method for Ratio Experiment. In order to study further the effects of different raw materials on the properties of green fly ash-based grouting materials, the orthogonal method usually used in material preparation was used for the design of ratio experiment. In the test, there are mainly four factors considered, namely, cement content, silica fume content, sodium silicate content, and calcium chloride content. The content of each raw material equals the ratio of its mass to the total mass of cement and fly ash (for example, if the cement content is 0.3 , then the cement mass/ (total mass of fly ash and cement) $=0.3$ ). Some ratio experiment details are given in Table 1.

The orthogonal test is an economical designing method for experiment with high efficiency. After the factors and their levels are determined, according to the basic designing principles of orthogonal test, the orthogonal test for grouting material based on green fly ash is designed through the orthogonal table with 5 factors and 4 levels (L1645) which is finally determined. In the orthogonal test which should have been supposed to include $1024(45=1024)$ groups of tests, 16 groups of tests were conducted. In these tests, the total mass of fly ash and cement is $1500 \mathrm{~g}$, and the dosage of other raw materials was calculated in proportion. The specific orthogonal ratio table is shown in Table 2.

2.3. Research on Material Property. Based on Table 2, green fly ash-based grouting materials are prepared, and the material property tests are carried out at the same time. In the process of coal mine grouting, the fluidity of green fly ash-based grouting materials in the slurry state and its 
TABLE 1: Ratio for green fly ash-based grouting material.

\begin{tabular}{lcccc}
\hline C & SF & SS & CC & W \\
\hline 0.7 & 0.02 & 0.01 & 0.01 & 0.4 \\
0.8 & 0.03 & 0.02 & 0.02 & 0.4 \\
0.9 & 0.04 & 0.03 & 0.03 & 0.4 \\
1 & 0.05 & 0.04 & 0.04 & 0.4 \\
\hline
\end{tabular}

C- cement, SF- silica fume, SS- sodium silicate, CC- calcium chloride, Wwater.

TABLE 2: Orthogonal test ratio table of green fly ash-based grouting material.

\begin{tabular}{lccccc}
\hline Group & FLA $(\mathrm{g})$ & SF $(\mathrm{g})$ & SS $(\mathrm{g})$ & CC $(\mathrm{g})$ & $\mathrm{W}(\mathrm{g})$ \\
\hline 1 & 1500 & 75 & 60 & 60 & 600 \\
2 & 1500 & 45 & 15 & 45 & 600 \\
3 & 1500 & 30 & 45 & 30 & 600 \\
4 & 1500 & 60 & 30 & 15 & 600 \\
5 & 1350 & 60 & 45 & 45 & 600 \\
6 & 1350 & 45 & 60 & 15 & 600 \\
7 & 1350 & 75 & 15 & 30 & 600 \\
8 & 1350 & 30 & 30 & 60 & 600 \\
9 & 1200 & 45 & 30 & 30 & 600 \\
10 & 1200 & 30 & 60 & 45 & 600 \\
11 & 1200 & 60 & 15 & 60 & 600 \\
12 & 1200 & 75 & 45 & 15 & 600 \\
13 & 1050 & 30 & 15 & 15 & 600 \\
14 & 1050 & 75 & 30 & 45 & 600 \\
15 & 1050 & 45 & 45 & 60 & 600 \\
16 & 1050 & 60 & 60 & 30 & 600 \\
\hline
\end{tabular}

strength when it is solidified are mainly considered. Therefore, based on the Test Methods for Basic Properties of Building Mortars (JGJ 70-2009), tests have been carried out on the fluidity the consistency of green fly ash-based grouting materials under the slurry state (during 1 to 3 mins after being mixed) and the uniaxial compressive strength of the materials after its being solidified (the materials were solidified into a cube with a size of $70.7^{*} 70.7$, and the cube was kept until it got the age required by the experiment at $98 \%$ of humidity and $20^{\circ} \mathrm{C}$ degree.)

2.3.1. Analysis of the Fluidity of the Materials. Consistency is a common parameter to show the fluidity of cement mortar, and its size can directly represent the fluidity of slurry. The greater the consistency parameter, the better the fluidity of slurry, and vice versa. In accordance with the national standards, a consistency testing system was used to test the fluidity of green fly ash-based grouting materials in the 16 groups of slurry with different proportions in the orthogonal experiment. The specific data of consistency testing are shown in Table 3.

To analyze the effect of raw materials on the fluidity of the grouting material, range analysis was conducted on the experimental results, and the details are shown in Figure 2. The range analysis result shows that the order of the influence degree the four factors have on the consistency of fly ash-based grouting materials is cement content $>$ sodium silicate content $>$ calcium chloride content $>$ silica fume content. The consistency is mainly affected by cement content and sodium silicate content. With the reduction in cement content (namely, the gradual increase of fly ash content), the consistency increases gradually and the material fluidity becomes better. With the increase in sodium silicate content, the consistency decreases gradually and so does the fluidity. The positive effect fly ash content has on the fluidity of materials mainly results from (1) the microaggregate effect of fly ash: the standard for the fineness of cement is 325 mesh, and among all the fly ash, $47.03 \%$ of the fly ash particles (from the Dananhu Power Plant in Xinjiang) is less than the standard. That is to say, nearly half of the fly ash particles are very tiny, which enables the fly ash to be more fully blended with cement and other materials and increase the fluidity of the material; (2) morphological effect: the shape of fly ash is like a very small round ball which plays a role similar to that of the "ball" in the slurry of fly ash-based grouting material, reducing the friction between particles inside the fly ash-based grouting material and, thus, improving the material fluidity. The negative effect of sodium silicate content on material fluidity is mainly due to the reaction of sodium silicate with water which produces $\mathrm{NaOH}$ and silicate acid insoluble in water, leading to a certain degree of false setting in the early stage of the grouting process and, thus, reducing the fluidity of the grouting material [25]. Wollastonite and calcium chloride have little influence on the fluidity of green fly ash-based grouting materials, and there is no obvious rule to follow. Silica fume and calcium chloride have little effect on the fluidity of green fly ash-based grouting materials, and no obvious rules are observed.

2.3.2. An Analysis of the Material Strength. The strength of the grouting material will directly affect the strength of the cement rock after the cementation of the material and the crushed surrounding rock. Therefore, for grouting technology, the strength of grouting material is a quite important performance indicator. A uniaxial compressive strength test was performed, respectively, on the material sample whose age was 7 days and 28 days through using the universal experimental machine of modal WDW-300.

The mean value of the compressive strength of cube specimens of this group was 1.3 times of the arithmetic mean value of the three specimens (accurate to $0.01 \mathrm{MPa}$ ). If the difference between either one of the maximum or minimum values of the three measured values and the median value exceeds $15 \%$ of the median value, the median value will be taken as the uniaxial compressive strength (USC) of this group of specimens regardless of the maximum and minimum value. If the difference between both of the maximum and minimum value and the median value exceeds $15 \%$ of the median value, then the test result is not effective. Finally, the uniaxial compressive strength of 7-day and 28-day samples and their difference represented by the $D$ value are obtained. The specific data are shown in Figure 3.

From the strength test results of green fly ash-based grouting materials, it can be seen that the cement content is still the major factor affecting the material, and the ratio of 
TABLE 3: Results of consistency testing for green fly ash-based grouting materials.

\begin{tabular}{|c|c|c|c|c|c|c|c|c|c|c|c|c|c|c|c|c|}
\hline Group & 1 & 2 & 3 & 4 & 5 & 6 & 7 & 8 & 9 & 10 & 11 & 12 & 13 & 14 & 15 & 16 \\
\hline Consistency $(\mathrm{cm})$ & 10.50 & 11.80 & 8.80 & 9.70 & 11.70 & 11.30 & 12.00 & 12.80 & 11.80 & 11.30 & 11.80 & 11.10 & 11.80 & 12.50 & 11.80 & 12.80 \\
\hline
\end{tabular}

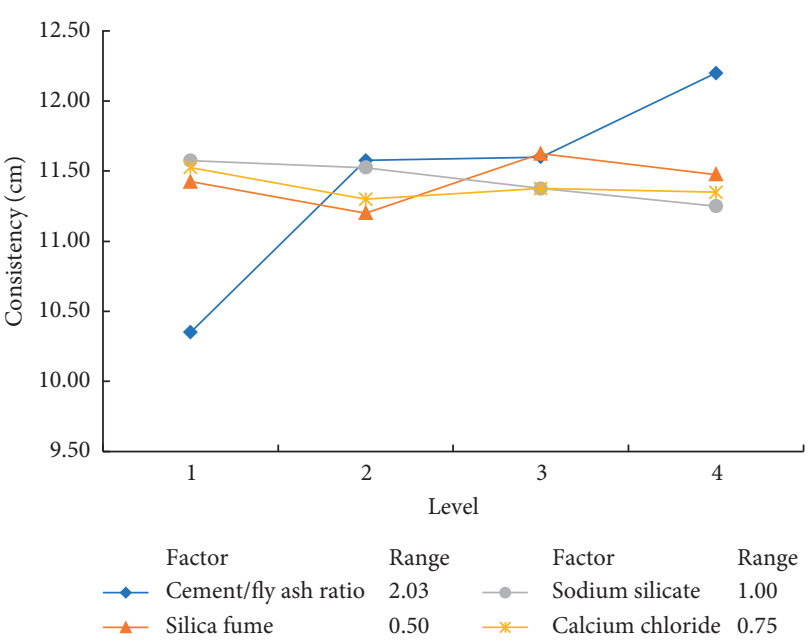

Figure 2: The analysis of the consistency of fly ash-based grouting materials in the slurry state.

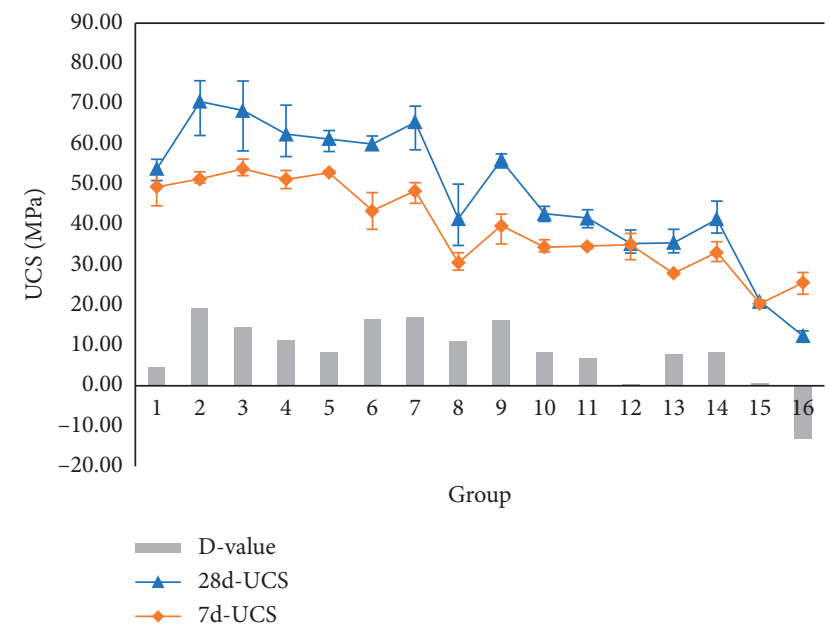

FIGURE 3: Strength of green fly ash-based grouting materials.

fly ash content to cement content determines the level of material strength to a large extent. The average strength of green fly ash-based grouting material without fly ash can reach the level of C60. The average strength of grouting materials with $10 \%$ of fly ash content can reach the level ranging from $\mathrm{C} 55$ to $\mathrm{C} 60$. Through adjusting the content of other materials, the strength of the grouting material with $10 \%$ of fly ash content can also reach the level of C65. The average strength of grouting materials with $20 \%$ of fly ash content can reach the level ranging from 40 to $\mathrm{C} 45$, and there are some groups of grouting materials whose strength can reach the level of C55. However, when the fly ash content reaches $30 \%$, the measured average strength of the grouting material can only reach the level of C25.
The influence from various aspects should be considered in the application of green fly ash-based grouting material in mine surrounding rock grouting reinforcement. Based on the analytic results of consistency and strength of fly ashbased grouting materials and with the actual demand from the mine and the design concept of technical feasibility, economy and rationality considered, the final proportion scheme for the grouting material in the mine were determined to be as follows: the fly ash content- 0.2, cement content- 0.8 , silica powder content- 0.03 , sodium silicate content- 0.01 , and calcium chloride- 0.03 .

\section{Schematic Design for Grouting Reinforcement}

3.1. The Geological Condition of the Permanent Refuge Chamber of the Mine. The Dananhu No. 1 Coal Mine is located at $89 \mathrm{~km}$ of Harrow Road, Hami City, Xinjiang Province. At present, $3 \#$ coal is being mined, and its average burial depth is $100 \mathrm{~m}$. The permanent refuge chamber of the mine is located between the Auxiliary Transportation Main Roadway and Crossheading of Return Air Main Roadway, and its specific position is shown in Figure 4. The roof and floor of the chamber are mainly composed of siltstone, charcoal mudstone, and pack sand, all of which have low strength. There are two mining disturbances resulting, respectively, from the mine development and from the stoping on the working face of 0301 , and the key structure of $3 \#$ coal which is shallowly buried is very weak. In addition, the phenomenon of stress concentration in the surrounding rock densely arranged in the tunnel chamber here is obvious. A combination of these phenomena led to the bad damage of the surrounding rock of the permanent refuge chamber and maintenance difficulties.

At present, the instability of the surrounding rock mainly lies in these aspects: serious rib spalling, roof deformation, obvious floor heave, crack development, and some water seepage in the permanent refuge chamber of the mine. For the details, please refer to Figure 5. For these problems, a variety of active support and reinforcement measures, such as bolt supporting, anchor cable, and guniting reinforcement, are adopted in the mine. However, these measures have very little effect on the recovery of the stability of the surrounding rock, and it is necessary to regularly do flitching and dinting to maintain the stability of the chamber.

An evaluation of the damage of the permanent refuge chamber has been conducted in view of the little effect of current support and reinforcement measures. The cross point method was used to measure the deformation of the surrounding rock, and the convergence of roof-to-floor and of the two sides of the rock and the rates of the convergence have been measured. Two fixed points with $10 \mathrm{~m}$ apart from each other were selected for measurement in the permanent refuge chamber. The measurement was taken every two days, 


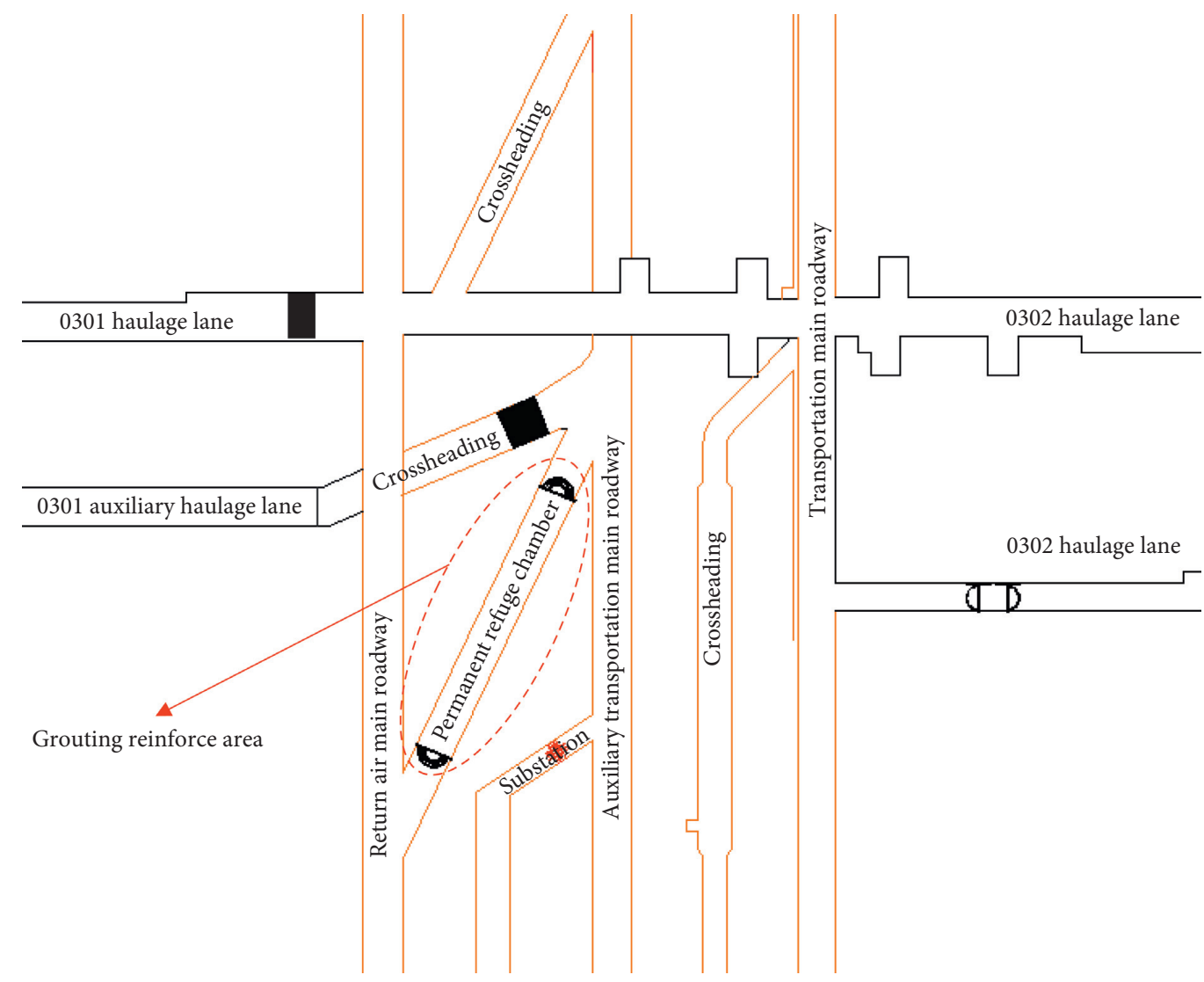

$\square$ Chamber

D Ventilation door

Airtight wall

Figure 4: Location arrangement of roadway.

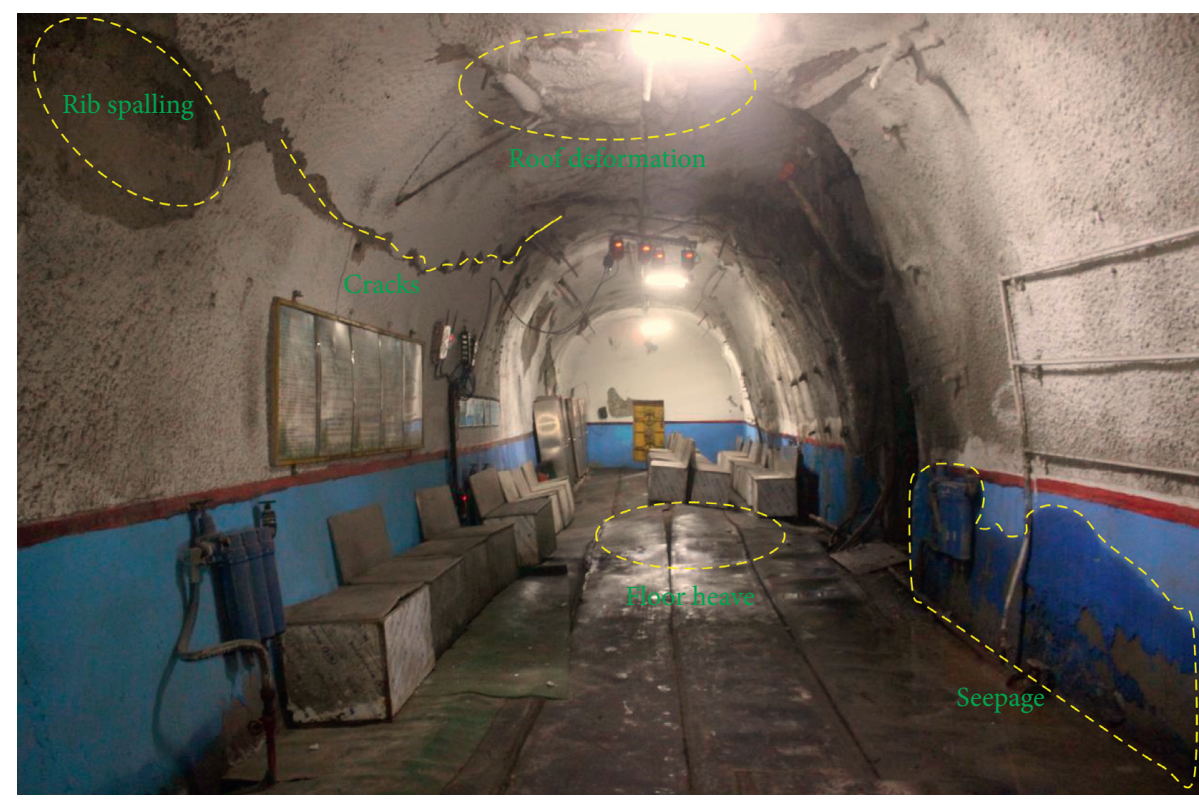

FIGURE 5: The instable conditions of the surrounding rock in the permanent refuge chamber. 
and the records were made. On this basis, the crack development in the surrounding rock was observed through borehole observation and knowing the crack development of the surrounding rock is important to make the specific scheme for grouting reinforcement. It was finally determined that the green fly ash-based grouting material should be used to reinforce the permanent refuge chamber to improve the integrity of the surrounding rock and ensure the stability of the permanent refuge chamber.

\subsection{Grouting Technology}

3.2.1. The Layout of the Grouting Hole and the Related Parameters. In the whole grouting process, the layout of grouting holes and the depth of the grouting hole affect directly the grouting and cementing result of surrounding rock. In this experiment, there are 5 grouting holes designed on the roof of the chamber, which are uniformly arranged at an angle of $30^{\circ}$. There are 2 grouting holes designed on the two sides, respectively, and on each side, the two holes are $1 \mathrm{~m}$ apart. The specific layout for the grouting hole is shown in Figure 6. Based on the previous result of borehole observation, the cracks within $4 \mathrm{~m}$ depth of the surrounding rock in the chamber are quite fully developed, and therefore, the depth of the grouting hole should be $4 \mathrm{~m}$. It is expected that a cementing layer of about $4 \mathrm{~m}$ in thickness will be formed around the chamber after the grouting operation.

3.2.2. Design for the Grouting Pipe. The grouting pipe is a very important part in the grouting process of surrounding rock in the roadway. In this experiment, the grouting hole is $4 \mathrm{~m}$ deep, and the grouting pipe is $3 \mathrm{~m}$ long. The grouting pipe is made of a steel pipe with $3 \mathrm{~m}$ length and $36 \mathrm{~mm}$ diameter. A fine iron wire is welded on the whole end of the grouting pipe which is $500 \mathrm{~mm}$ long to increase the friction of enwinding cotton and linen through which the grouting pipe is fixed. At the bottom of the pipe is welded the ball valve interface, in the front of which is installed a tray with $10 \mathrm{~mm}$ in thickness, for the purpose of preventing the blocked cotton and linen from being pushed out by the high grouting pressure. For the remaining part of the front of the grouting pipe, the slurry outlets are uniformly arranged, and the slurry outlets are $200 \mathrm{~mm}$ apart from each other. For the schematic diagram of grouting pipe design, please refer to Figure 7.

3.2.3. Grouting Procedure. As is shown in Figure 8, before the beginning of the grouting process, all preparations have been made to ensure a safe and smooth operation of grouting. Firstly, the roof and the two sides of the chamber should be supported by bolt, with the roof fixed by an extended anchor cable and the whole wall of the chamber sprayed with concrete. Three days later, when the grouting layer was dry and stable, the construction for the grouting hole began. For grouting, taking the construction of a single grouting hole for example, the specific process sequence is as follows: cotton and linen enwinding, grouting pipe inserting, grouting pipe connecting, material mixing, pump starting, grouting under low pressure, grouting pressure stabilizing, grouting pressure elevating, end of the grouting process, grouting pipe disconnecting, ball valve closing, and grouting pipe cleaning. Due to the limited space of the chamber, a mixing tank was used to prepare the green fly ash-based grouting material on the spot. At the same time, a hand mixer was also adopted for material mixing. The slurry resistance generated in the grouting process is gradually increasing, with the characteristics of large amount of grouting and small resistance in the initial stage and small amount of grouting and large resistance in the later stage. Therefore, the pneumatic grouting pump for mining use in this construction, produced by Zhenjiang Great Wall Grouting Equipment Co., Ltd., is of model $2 \mathrm{ZBQ} 40 / 11$ whose performance can meet the demand of this grouting process. The slurry-conveying pipe is made of a plastic pipe of $40 \mathrm{~mm}$ diameter. Due to the high pressure the walls of the pipe have to take during the grouting process, the high-pressure plastic pipe of $20 \mathrm{MPa}$ is adopted for this grouting.

\section{Testing for the Cementing Result after the Grouting Process in the Surrounding Rock of the Roadway}

The whole grouting process in the permanent refuge chamber officially began on the 11th of July and ended on the 13rd of July. In order to test the cementing effect of green fly ash-based grouting materials in the grouting process in the surrounding rock of the roadway, a comprehensive analysis of the cementing effect of green fly ash-based grouting materials and the surrounding rock through such ways such as borehole observation, monitoring of the displacement in the surrounding rock, and drilling for core was conducted.

4.1. Grouting Technology. Before the grouting process began, borehole observation was performed on the surrounding rock of the chamber, and the specific peeping results are shown in the Figure 9(a). As is shown in Figure 9(a), the cracked area is marked with a red dotted line. It can be seen from the figure that, within the range of $0 \mathrm{~m}$ to $4 \mathrm{~m}$ of the surrounding rock, the cracks in the surrounding rock are more fully developed and are randomly distributed in the rock. The cracks in the surrounding rock are not obvious in the figures of the drilling results. However, considering that the coal and rock of $3 \#$ coal seam are quite soft, leading to them getting easily broken by external disturbance when there are fully developed cracks in the coal. The results of surrounding rock borehole observation after the grouting process are shown in Figure 9(b), and the cementation area is marked with blue color in the figure. It can be seen from the figure that the integrity of the surrounding rock has increased on the whole, and the cracks have been greatly reduced. Most of the cracking and microcracking areas are filled with the green fly ash-based grouting material which is 


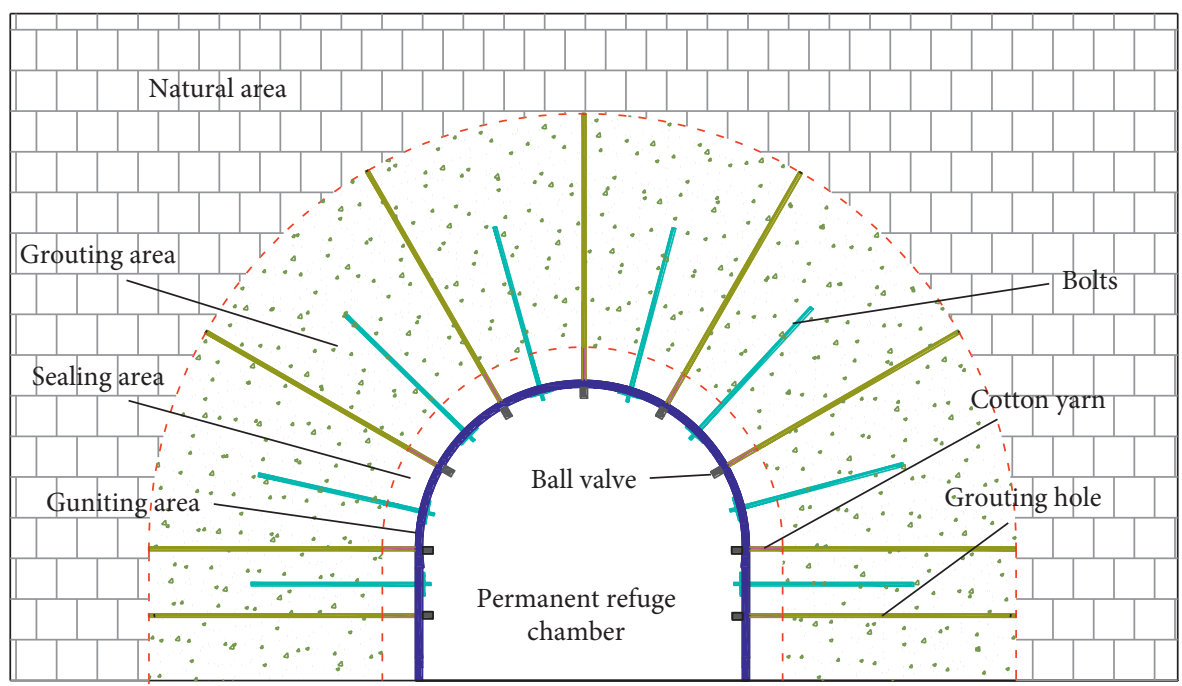

FIgURE 6: The layout of grouting hole of the permanent refuge chamber.

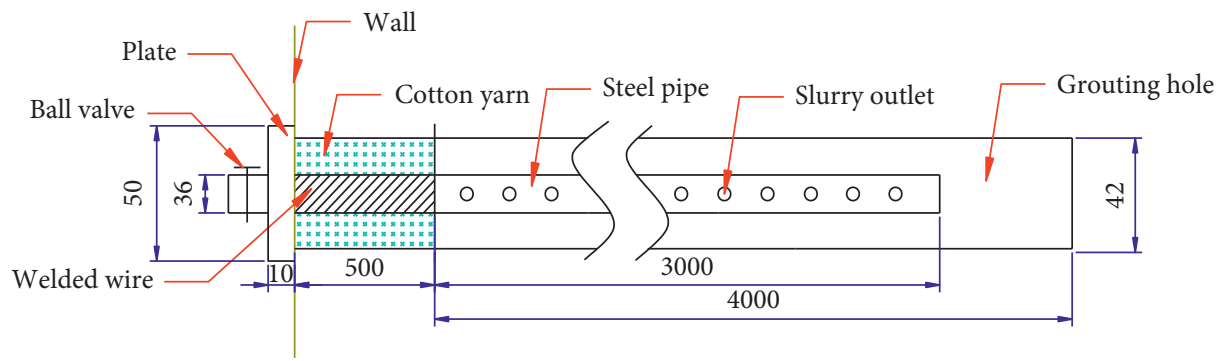

Figure 7: The schematic diagram of grouting pipe design.

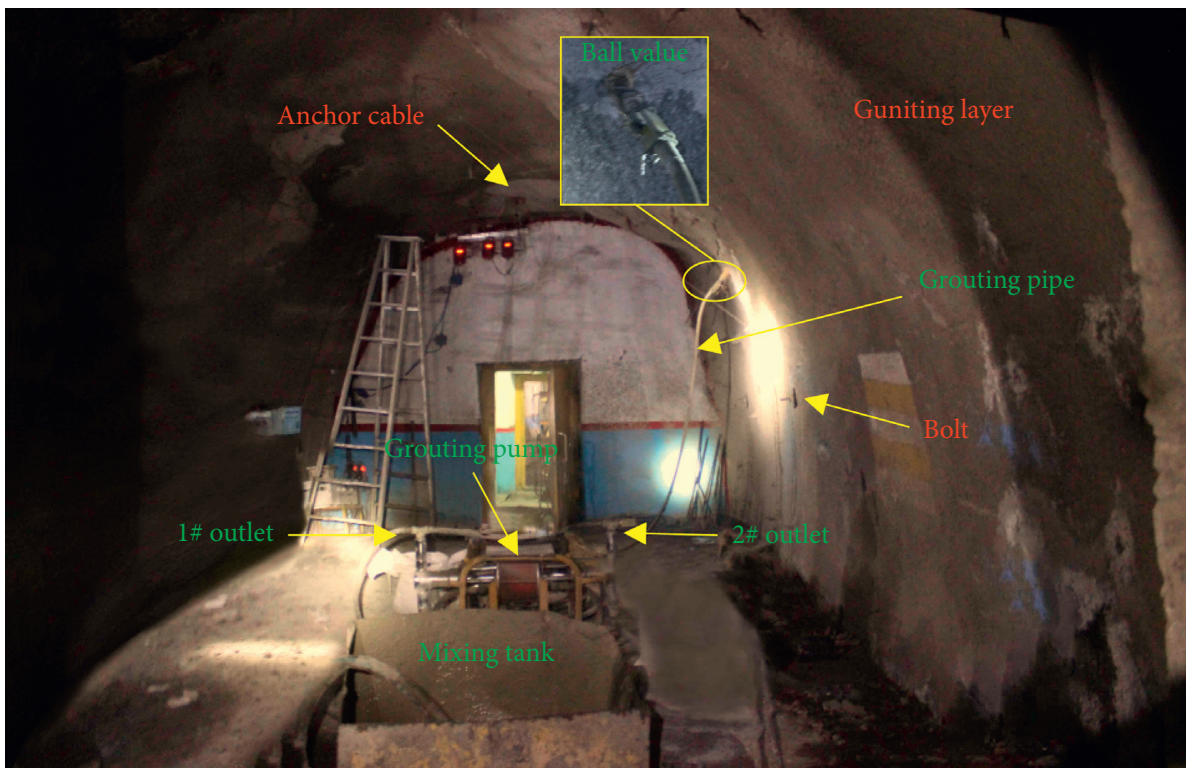

FIGURE 8: Grouting site.

silvery gray. The cemented surrounding rock has a better structure on the whole, and the area of stress concentration in the surrounding rock is greatly reduced, and the force is more uniformly distributed, which is conducive to the maintenance of the chamber.
4.2. The Observation Result of Cementation of the Surrounding Rock after the Grouting Process. To observe the cementation result of the green fly ash-based grouting material and the surrounding rock of the roadway more clearly, a drill was used to observe the surrounding rock after the grouting 


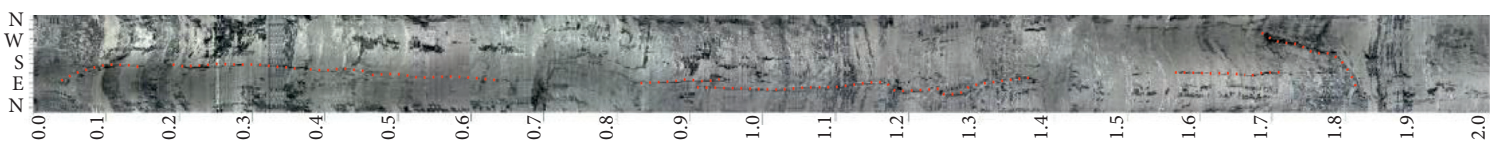

(a)

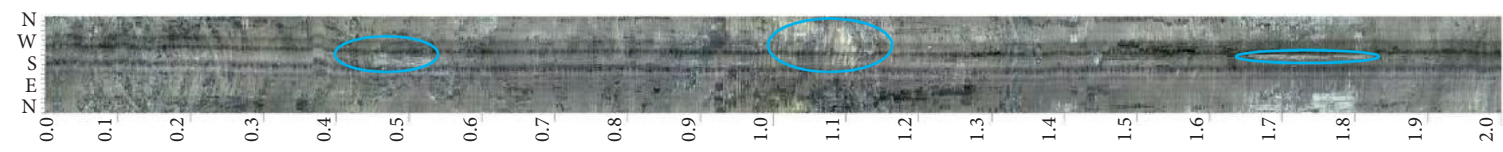

(b)

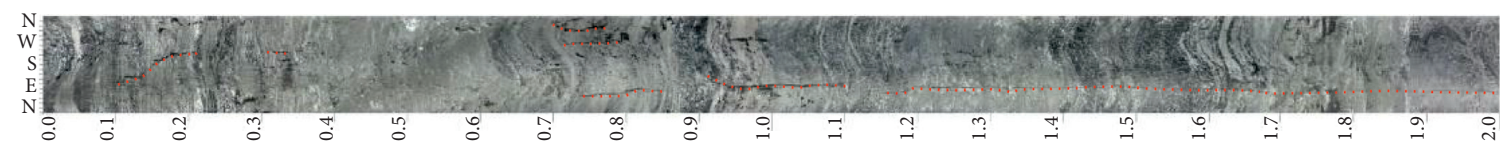

(c)

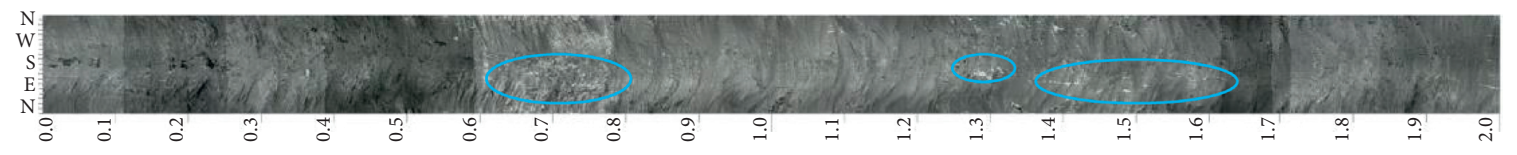

(d)

FIGURE 9: Borehole observation picture of the surrounding rock before and after the grouting process: (a) 0 2 m-before grouting; (b) 0 2 mafter grouting; (c) 2 4 m-before grouting; and (d) 2 4 $\mathrm{m}$-after grouting.

process through coring. The drill hole and core before and after the grouting process are shown in Figure 10, from which it can be clearly seen that the core is very broken and that there is no mass of columnar in the core of the surrounding rock before the grouting process. However, after the grouting process, it can be clearly observed that there is a complete mass formed by the cementation of green fly ashbased grouting material and the cracking surrounding rock. Furthermore, green fly ash-based grouting material can penetrate into the small cracks of the surrounding rock and cement with these small cracks. In a word, the green fly ashbased grouting material can cement with the coal and rock well, increasing the integrity of the coal and rock. Also, the improvement of the integrity of the coal and rock is the key part of the maintenance of the chamber.

4.3. The Observation of the Convergence of Roof-To-Floor. The deformation of the surrounding rock is a very important parameter which can well reflect the deformation degree and rate of the roadway and the chamber. Therefore, there were two points arranged in the chamber to test the convergence of roof-to-floor and of the two sides between each other. The deformation testing and observation for the surrounding rock of the chamber had been going on during the whole grouting process and even after the grouting process when the surrounding rock was becoming stabilized. The mean value of the two points can represent the deformation of the surrounding rock, and the details are shown in Figure 11. From Figure 11(a), it can be seen that the convergence rate of the roof-to-floor in the chamber was about $7 \mathrm{~mm} / \mathrm{d}$ before the grouting process and the change of the rate was not seen until the 11th of July. On the $21 \mathrm{st}$ of July, the rate was gradually reduced to $3 \mathrm{~mm} / \mathrm{d}$ which tended to stay after. The deformation of the two sides

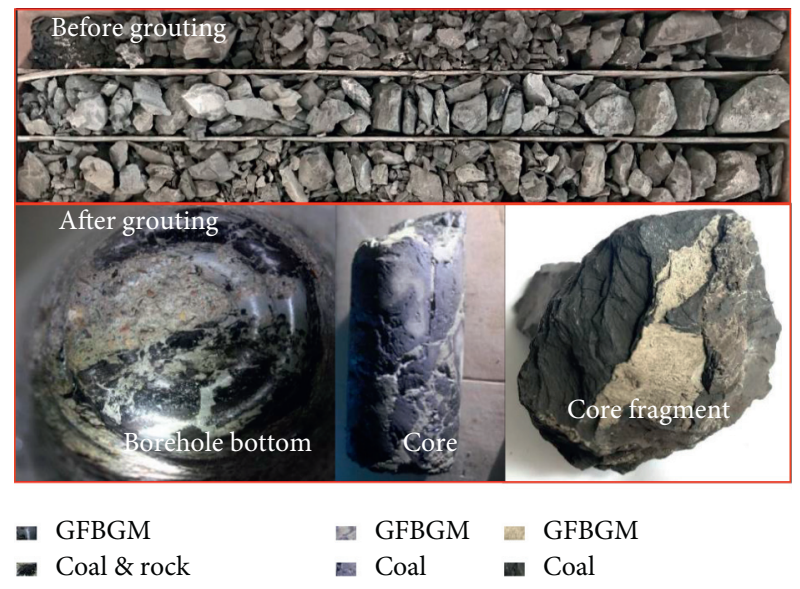

Figure 10: Borehole core samples before and after grouting.

of the chamber is shown in the Figure 11(b). The displacement rate of the two sides is smaller than that of the roof-to-floor. Yet, the variation trend of the change of the rate is almost consistent with that of the roof-to-floor.

As Figure 11 reflects, the whole operation process of grouting shows the variation trend from stabilizing to gradual weakening and to stabilizing again. Therefore, the whole grouting reinforcement and cementation process can be divided into three stages: the initial stage, the cementation stage, and the reinforcing stage for rock stabilizing. In the initial stage which lasted until the 11th of July, the grout has not entered the surrounding rock, and thus, the reaction between the grout and the rock has not begun. During the cementation stage which lasted from the 11th to 21 st of July, the slurry entered the surrounding rock and the cementation process had begun until the slurry became solid. During the reinforcing stage 


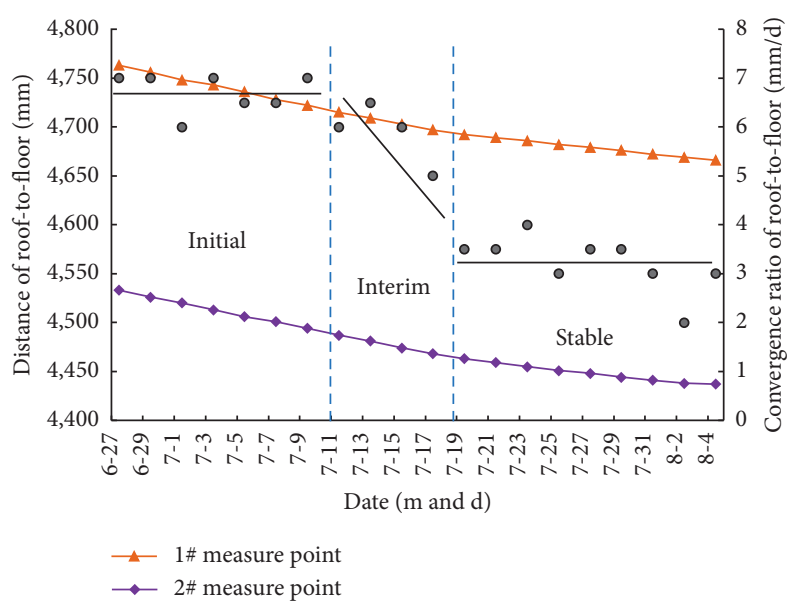

(a)

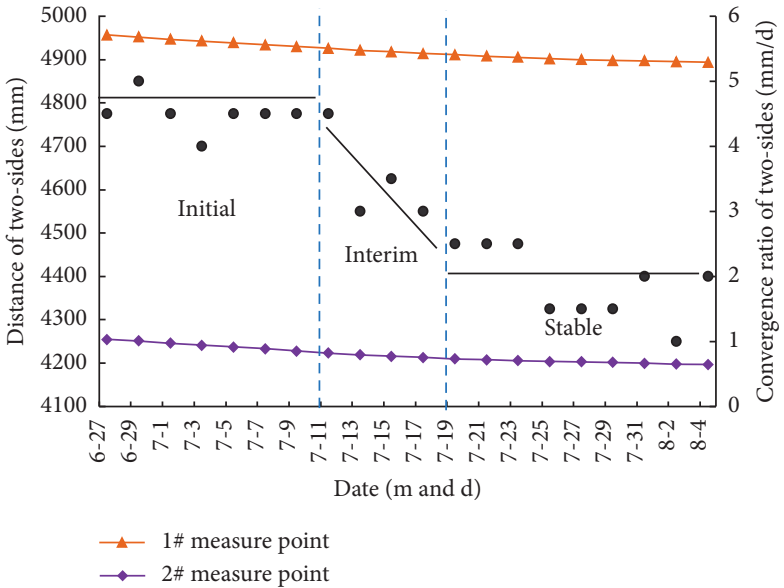

(b)

FiguRE 11: The observation result of the deformation of the surrounding rock in the chamber: (a) convergence of roof-to-floor; and (b) convergence of the two sides.

for rock stabilizing which began after the 21 st of July, the slurry became completely solid or an entire load bearing structure was formed after the cementation. It is worth noting that how long the cementing stage would last was greatly affected the mining environment and material performance. Normally, the green fly ash-based grouting material can reach an initial setting time period with 1 day, and it can only take 7 days for a cemented rock with a certain strength to form. However, the complexity of the environment inside the surrounding rock in the coal mine may prolong the cementation process to about 10 days.

\section{Numerical Simulation for Grouting Reinforcement Technology}

5.1. Modal Establishing. Based on the geological conditions of Dananhu No. 1 Coal Mine, it can be made sure that the average burial depth of 3\# coal seam is $102.63 \mathrm{~m}$. Since the permanent refuge chamber is in the middle of the coal seam, $102.63 \mathrm{~m}$ can be considered as the burial depth of the chamber. UDEC, a numerical simulation software, was used for the establishment of a model to simulate the real grouting process. Considering the geometric ratio between the actual size of the chamber and its burial depth, the simulation model is built with $30 \mathrm{~m}$ thickness and $30 \mathrm{~m}$ width, as is shown in Figure 12. This model can give us a better and direct view of the effect of the fly ash-based grouting material on the cementation and reinforcement of the surrounding rock. An initial stress applied to the model can equivalently replace the rock strata from the land surface to the depth of $85 \mathrm{~m}$ below the surface.

The initial stress can be created through using INSITU to apply stresses such as gravity and tectonic stress to the model. The vertical stress and the horizontal stress can be calculated as follows:

$$
V_{s}=\rho g h,
$$

where $V_{s}$ is the vertical stress, $\rho$ is the average density of rock $\left(2400 \mathrm{~g} / \mathrm{cm}^{3}\right), g$ is the gravitational acceleration $(9.8 \mathrm{~N} / \mathrm{kg})$, and $h$ is the depth from the land surface to the chamber.

$$
H_{s}=V_{s} * S P C
$$

where $H_{s}$ is the horizontal stress and SPC is the Side Pressure Coefficient (1.2).

In the modal, there are four points selected for monitoring. Also, these points are named with MP. MP \#1 and MP \#2 represent the center of the roof and of the floor, respectively. MP \#3 and MP \#4 represent, respectively, the two positions of the two sides each of which is $1 \mathrm{~m}$ high from the floor. The shallow-hole grouting means the grouting reinforcement measure taken on the roof and two sides of the chamber, while the deep-hole grouting means the grouting reinforcement measure of $8 \mathrm{~m}$ hole depth.

\subsection{Analysis and Discussion of the Effect of the Grouting Process} on the Surrounding Rock Reinforcement. In Figure 13, the changing curve reflects the displacement change of each monitored point, and the positive number means the displacement towards the inside of the chamber. From Figure 13(a), it can be seen that the roof deformation is quite large without grouting reinforcement. In the modal, when there are 200,000 steps, the displacement of this monitored point increases sharply, indicating that the rock at this point have been detached from the roof. The displacement of the roof is much smaller after shallow-hole grouting reinforcement than that of the roof without grouting. Compared with shallow-hole grouting, the deep-hole grouting can better strengthen and improve the carrying capacity of the roof and, thus, reduce the roof deformation. Due to the symmetry of the model, the displacement of the two sides of the chamber stays the same. As can be seen in Figure 13(b), shallow-hole grouting has weak control over the deformation of two sides, and there is almost no difference of the amount of floor heave with or without grouting. However, 


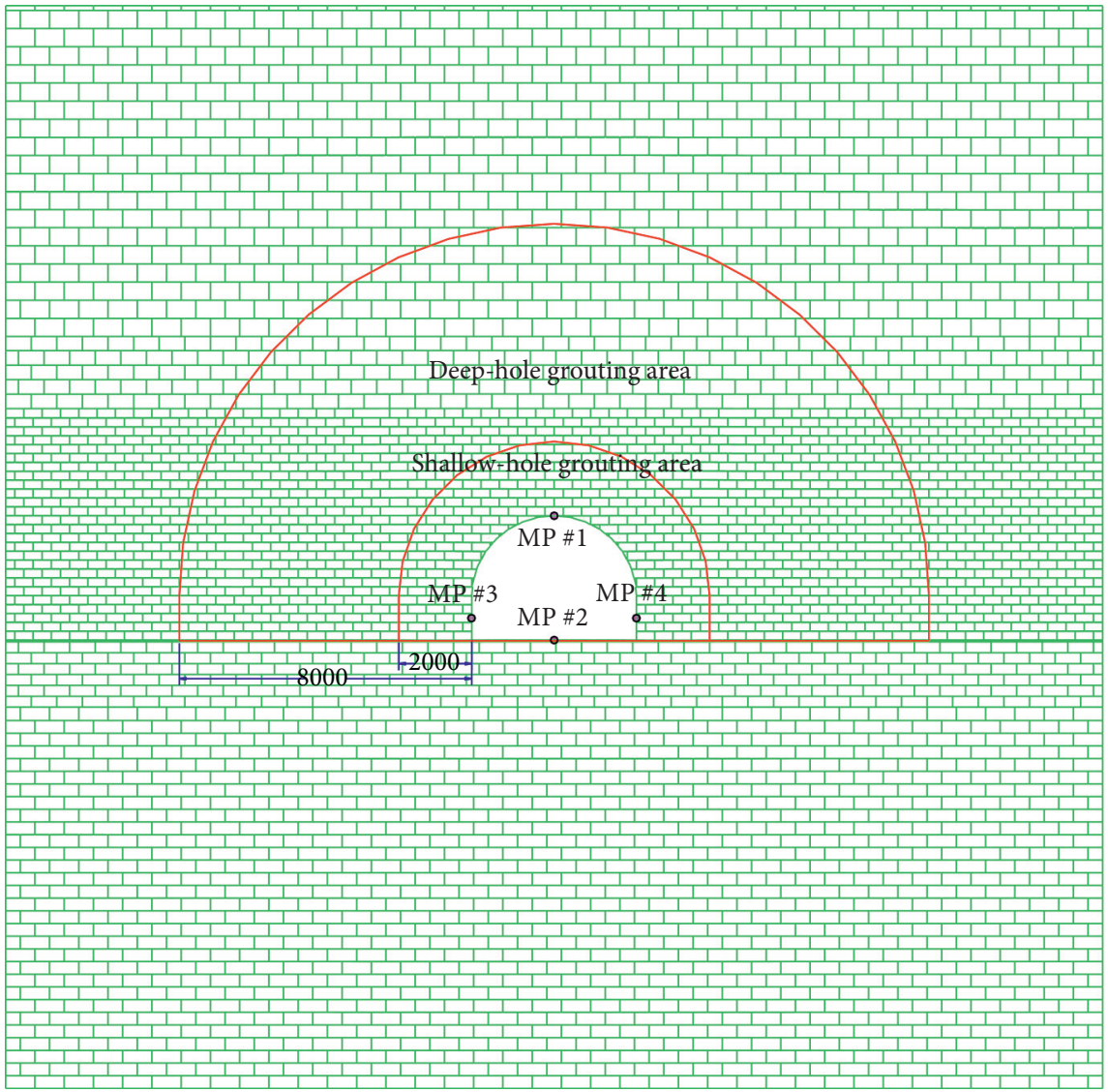

FIGURE 12: Grouting model for the surrounding rock in the permanent refuge chamber.

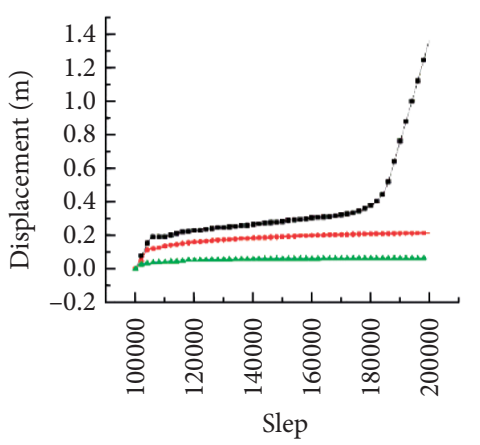

- Natural

$\rightarrow$ Shallow hole

$\rightarrow$ Deep hole

(a)

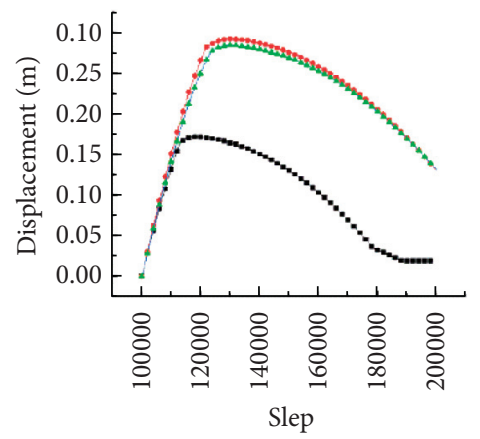

- Natural

$\rightarrow$ Shallow hole

$\longrightarrow$ Deep hole

(b)

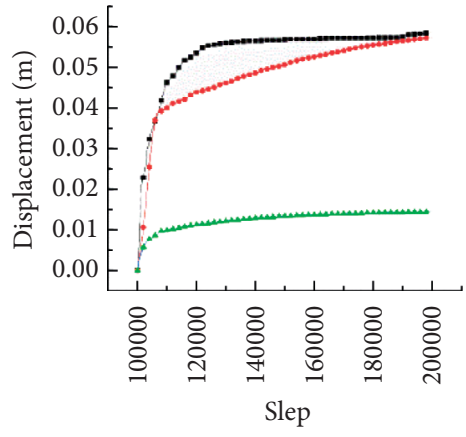

- Natural

$\rightarrow$ Shallow hole

$\rightarrow$ Deep hole

(c)

FiguRE 13: Surrounding rock displacement curve in different grouting methods: (a) Roof; (b) floor; and (c) two sides.

the deep-hole grouting has a good control over the deformation of the whole surrounding rock, and there is apparent reduction in the displacement after the deep-hole grouting process, which is obviously shown in the figure. Through the grouting operations on the roof and the two sides of the chamber, the integrity of surrounding rocks in the grouting area improved and the carrying capacity increased. However, the floor without being grouted became a problem for the chamber support at this time, and the floor heave increased. The grouting process showed no obvious influence on the deformation of the floor, as is shown in Figure 13(c). In a word, although the grouting operation results in some floor deformation, it reduces the deformation of the roof and of the two sides of the chamber. The floor deformation can be reduced through some dinting work in the mine, which is more economical and efficient compared with the control over the deformation of the roof and of the two sides of the chamber. 
The green fly ash-based polymer serves as a good and effective grouting material in the industrial application, and therefore, it can be inferred that green fly ash-based polymer as a grouting material has good cementation effect on the surrounding rock of the mine roadway, which can greatly increase the integrity and the carrying capacity of the surrounding rock and, thus, improve the its stability. However, the shallow-hole grouting technology commonly for industrial use is not applicable to all kinds of surrounding rock of the mine. Therefore, it is necessary to make some specific adjustments to the grouting technology based on the specific conditions of the surrounding rock in the chamber and roadway. From the laws obtained from numerical simulation of grouting reinforcement, these rules can be obtained: for the control of the surrounding rock in the roof, the shallowgrouting can achieve a more ideal effect; when there is great difficulty in the control of the two sides, deep-hole grouting should be combined with shallow-hole grouting to enhance the stability of surrounding rock of the two sides; the area without being grouted in the chamber and roadway will become a new area needing attention and control. Therefore, it is necessary to design the grouting process for the mine based on the specific conditions of the surrounding rock in the chamber.

\section{Conclusions}

In this study, methods including an orthogonal test, on-site investigation, theoretical analysis, engineering application, and numerical simulation were used to analyze the application of green fly ash-based polymer in mine grouting, and the mechanism of the grouting reinforcement is revealed. The following conclusions can be drawn:

(1) The green fly ash-based polymer has good fluidity and strength, meeting the requirements for mine grouting materials. When the grouting material is prepared with fly ash content of 0.2 , cement content of 0.8 , silica powder content of 0.03 , sodium silicate content of 0.01 , and calcium chloride content of 0.03 , it is economical with a good performance as a grouting material for the coal mine.

(2) The whole grouting process can be divided into three stages: the initial stage, the cementation stage, and the reinforcing stage for rock stabilizing. The cementation stage is greatly affected by the mining environment and usually extends to about 10 days.

(3) The green fly ash-based polymer can penetrate fully into the cracks of the surrounding rock and is fully cemented with it, increasing the integrity of the surrounding rock and improving its carrying capacity.

(4) There is a great need for a reasonable and specific design for the grouting process based on the conditions of the surrounding rock in the mine when the green fly ash-based polymer is used as a grouting material. Shallow-hole grouting should be used for the reduction in the roof deformation, and deep-hole grouting should be adopted for the deformation of the two sides in the case that the deformation is very large. If there is some area without being grouted in the grouting process, this area will need some control.

\section{Data Availability}

The data used to support the findings of this study are available from the corresponding author upon request.

\section{Conflicts of Interest}

The authors declare that they have no conflicts of interest regarding the publication of this paper.

\section{Acknowledgments}

The authors acknowledge the National Natural Science Foundation of China (51674242) for the financial support and Dananhu No.1 Coal Mine and CHN ENERGY Investment Group Co Ltd for the great help provided in in situ test.

\section{References}

[1] S. R. Ge, H. T. Liu, J. L. Liu, and H. S. Hu, "Energy consumption analysis and energy saving strategies for coal mine production in China," Journal of China University of Mining \& Technology, vol. 47, pp. 9-14, 2018.

[2] Q. Wu, K. Tu, Y. F. Zeng, and S. Q. Liu, "Discussion on the main problems and countermeasures for building an upgrade version of main energy (coal) industry in China," Journal of China Coal Society, vol. 44, pp. 1625-1636, 2019.

[3] Y. J. Wang, "Energy industrial chain integration and production efficiency-taking vertical integration of coal and electricity as an example," Journal of Beijing Institute of Technology (Social Sciences Edition), vol. 21, pp. 29-38, 2019.

[4] Y. P. Wu, "Analysis and suggestion on development of coal power joint venture in China," Coal Engineering, vol. 48, pp. 138-141, 2016.

[5] Q. Wu, H. Liu, H. Zhao, M. Zhang, and Y. Zeng, "Discussion on the nine aspects of addressing environmental problems of mining," Journal of China Coal Society, vol. 44, pp. 17-29, 2019.

[6] X. J. Wang, Z. Q. Hu, Q. F. Hu, and C. Chen, "Evolution and self-healing characteristic of land ecological environment due to super-large coalface mining in windy and sandy region," Journal of China Coal Society, vol. 40, pp. 2166-2172, 2015.

[7] X. C. Zhang and Y. B. Meng, "Brief analysis on present situation of comprehensive utilization of fly ash in China," Inorganic Chemicals Industry, vol. 52, pp. 1-5, 2020.

[8] M. C. G. Juenger, F. Winnefeld, J. L. Provis, and J. H. Ideker, "Advances in alternative cementitious binders," Cement and Concrete Research, vol. 41, no. 12, pp. 1232-1243, 2011.

[9] M. Ahmaruzzaman, "A review on the utilization of fly ash," Progress in Energy and Combustion Science, vol. 36, no. 3, pp. 327-363, 2010.

[10] A. Palomo, M. W. Grutzeck, and M. T. Blanco, "Alkali-activated fly ashes," Cement and Concrete Research, vol. 29, no. 8, pp. 1323-1329, 1999. 
[11] L. Xiong, Z. Wan, Y. Zhang, F. Wang, J. Wang, and Y. Kang, "Fly ash particle size effect on pore structure and strength of fly ash foamed geopolymer," Advances in Polymer Technology, vol. 2019, Article ID 1098027, 10 pages, 2019.

[12] D. Xuan, J. Xu, B. Wang, and H. Teng, "Borehole investigation of the effectiveness of grout injection technology on coal mine subsidence control," Rock Mechanics and Rock Engineering, vol. 48, no. 6, pp. 2435-2445, 2015.

[13] N. Cristelo, E. Soares, I. Rosa et al., "Rheological properties of alkaline activated fly ash used in jet grouting applications," Construction and Building Materials, vol. 48, pp. 925-933, 2013.

[14] K.-Y. Show, J.-H. Tay, and A. T. C. Goh, "Reuse of incinerator fly ash in soft soil stabilization," Journal of Materials in Civil Engineering, vol. 15, no. 4, pp. 335-343, 2003.

[15] J. X. Zhang, Y. N. Sun, Z. D. Sun, Z. M. Wang, and Y. Y. Zhang, "Analysis of macroscopic mechanical properties and mechanism of coal dust/polymer composite grouting material," Chinese Journal of Rock Mechanics and Engineering, vol. 38, pp. 2889-2897, 2019.

[16] F. Sha, S. C. Li, R. T. Lin, Q. S. Zhang, Z. F. Li, and H. J. Liu, "Performance and engineering application of effective microfine cement-based grout (EMCG) for water-rich sand strata," Chinese Journal of Rock Mechanics and Engineering, vol. 38, pp. 1420-1433, 2019.

[17] J. W. Xia, L. Zhang, Y. Z. Yang, and L. L. Yu, "Experimental study on durability of various grouting materials," Journal of Huazhong University of Science and Technology (Natural Science Edition), vol. 46, pp. 99-104, 2018.

[18] F. Rosquoët, A. Alexis, A. Khelidj, and A. Phelipot, "Experimental study of cement grout: rheological behavior and sedimentation," Cement and Concrete Research, vol. 33, no. 5, pp. 713-722, 2003.

[19] P. Duxson, A. Fernández-Jiménez, J. L. Provis, G. C. Lukey, A. Palomo, and J. S. J. van Deventer, "Geopolymer technology: the current state of the art," Journal of Materials Science, vol. 42, no. 9, pp. 2917-2933, 2007.

[20] T. Bakharev, "Geopolymeric materials prepared using Class F fly ash and elevated temperature curing," Cement and Concrete Research, vol. 35, no. 6, pp. 1224-1232, 2005.

[21] D. Hardijito, S. E. Wallah, D. M. J. Sumajouw, and B. V. Rangan, "On the development of fly ash-based geopolymer concrete," Materials Journal, vol. 101, no. 6, pp. 467-472, 2004.

[22] J. S. J. V. Deventer, J. L. Provis, and P. Duxson, “Technical and commercial progress in the adoption of geopolymer cement," Minerals Engineering, vol. 29, pp. 89-104, 2012.

[23] P. Chindaprasirt, T. Chareerat, and V. Sirivivatnanon, "Workability and strength of coarse high calcium fly ash geopolymer," Cement and Concrete Composites, vol. 29, no. 3, pp. 224-229, 2007.

[24] G. S. Ryu, Y. B. Lee, K. T. Koh, and Y. S. Chung, "The mechanical properties of fly ash-based geopolymer concrete with alkaline activators," Construction and Building Materials, vol. 47, pp. 409-418, 2013.

[25] Y. F. Hou, D. M. Wang, Q. Li, and H. B. Lu, "Effect of water glass performance on fly ash-based geopolymers," Journal of the Chinese Ceramic Society, vol. 36, no. 1, pp. 61-68, 2008. 